\title{
PELATIHAN DAN PENDAMPINGAN FOTOGRAFI SEBAGAI UPAYA PENINGKATAN KUALITAS DOKUMENTASI DI DESA WISATA NGERANGAN
}

\author{
S. I. Khasanah ${ }^{1}$, J. Istiyanto ${ }^{2}$, S. N.Muhammad ${ }^{3}$, W.B. A. Shevalinzi ${ }^{3}$, A. Nurdin ${ }^{4, *}$ \\ ${ }^{1}$ Staf Pengajar Program Studi D3 Teknologi Pengecoran Logam, Politeknik Manufaktur Ceper \\ ${ }^{2}$ Staf Pengajar Program Studi D3 Manajemen Industri, Politeknik Manufaktur Ceper, \\ ${ }^{3}$ Mahasiswa Program Studi D3 Manajemen Industri, Politeknik Manufaktur Ceper \\ email : nurdin@polmanceper.ac.id*
}

\begin{abstract}
ABSTRAK
Berawal dikenal sebagai desa cikal bakal angkringan, mulai pertengahan Tahun 2021 Desa Ngerangan melalui Badan Usaha Milik Desa atau BUMDes Ngerangan Jaya sedang mengembangkan Desa Wisata Ngerangan dengan memanfaatkan potensi setiap wilayah dusun. Kurangnya pengetahuan tentang pemanfataan teknologi informasi menjadi salah satu permasalahan dalam pengembangan desa wisata ini. Strategi pemanfaatan media sosial sebagai media digital marketing merupakan salah satu contoh pemanfaatan teknologi informasi. Dokumentasi berupa foto sebagai obyek promosi harus mampu menarik perhatian bagi sesama pengguna media sosial, sehingga foto tersebut harus berkualitas baik dan menarik. Tujuan dari pengabdian ini yaitu memeberikan pembekalan, pelatihan dan pendampingan teknik fotografi dan editing terhadap anggota aktif Desa Wisata Ngerangan. Kegiatan ini dilaksanakan di Balai Desa Ngerangan dengan peserta pengurus utama PKK setiap Dusun di Desa Ngerangan. Kegiatan diawali dengan pemaparan tujuan pengabdian ini, selanjutnya pembekalan, praktik teknik fotografi, dan praktik editing foto. Hasil dan evaluasi kegiatan ini dipantau melalui Media Sosial Whatsapp Grup. Hasil pengabdian ini menunjukkan peningkatan kemampuan peserta dalam fotografi dan editing sebelum dan sesudah yang layak digunakan sebagai obyek promosi maupun konten dimedia sosial.
\end{abstract}

Kata Kunci: Desa Wisata, Media Sosial, Fotografi

\begin{abstract}
Starting from being known as the forerunner village of angkringan, starting in mid-2021, Ngerangan Village through the Village Owned Enterprise or BUMDes Ngerangan Jaya is developing the Ngerangan Tourism Village by utilizing the potential of each hamlet area. Lack of knowledge about the use of information technology is one of the problems in the development of this tourist village. The strategy of using social media as a digital marketing medium is one example of the use of information technology. Documentation in the form of photos as promotional objects must be able to attract the attention of fellow social media users, so the photos must be of good quality and attractive. The purpose of this community dedication is to provide debriefing, training and assistance in photography and editing techniques to active members of the Ngerangan Tourism Village. This activity was carried out at the Ngerangan Village Hall with participants from the main Family Welfare Empowerment management in each hamlet in Ngerangan Village.
\end{abstract}


The activity begins with the presentation of the purpose of this service, then briefing, practice of photography techniques, and photo editing practices. The results and evaluation of this activity are monitored through Whatsapp Group Social Media. The results of this community dedication shown an increase in participants' abilities in photography and editing are worthy of being used as objects on social media.

Keywords: Tourism Village, Social Media, Photograph

\section{PENDAHULUAN}

Pariwisata ditinjau dari manfaatnya merupakan salah satu sektor penggerak ekonomi, salah satu bentuk pariwisata yang sedang berkembang di Indonesia yaitu desa wisata. Kawasan pedesaan yang memiliki karakteristik khusus dengan beberapa faktor pendukung seperti makanan khas berpotensi menjadi desa wisata (Zakaria \& Suprihardjo, 2014). Usaha mendukung pengembangkan desa wisata, diperlukan kegiatan pengenalan melalui pemasaran atau promosi sebagai usaha untuk menarik wisatawan (Nurhayati, 2018). Perkembangan informasi sosial mulai diperhatikan sejak munculnya revolusi industri 4.0 (Atina, Mahmudi, \& Abdillah, 2021), terutama di negara sedang berkembang (termasuk Indonesia) sesuai peningkatan pemanfaatan Internet of Things atau IoT (Atina \& Mahmudi, 2019). Besarnya penggunaan internet saat ini telah mengubah strategi tentang informasi, salah satunya strategi pemasaran atau promosi yang saat ini cendurung dilakukan melalui media digital (Arifah, 2015) untuk memberikan informasi tentang yang dipromosikan kepada calon konsumen (ES., Rahmi, \& Aditya, 2017). Dalam media digital sebagai promosi atau disebut digital marketing saat ini banyak dilakukan pada platform media sosial (Dewanti \& Solihin, 2021).

Pada perkembangannya, kualitas dokumentasi pada suatu platform media sosial merupakan aspek yang mempengaruhi ketertarikan pengguna lainnya (Tanjung, 2016), sehingga dokumentasi atau dalam hal ini disebut fotografi merupakan aspek yang penting. Ditinjau dari segi etimologinya fotografi merupakan kegiatan yang berhubungan dengan gambar atau tulisan (grafis) menggunkan media cahaya (foto). Melalui fotografi, seseorang dapat membuat sebuah dokumentasi dari kejadian-kejadian disekitarnya sebagai media informasi. Pengetahuan tentang dasar fotografi (misalnya efek blur dan pencahayaan) merupakan bekal untuk mendapatkan kualitas yang baik (Murwonugroho \& Atwinita, 2020). Selain teknik dasar, proses editing fotografi juga dibutuhkan untuk mendapatkan tampilan yang lebih menarik dan merancang informasi komunikasi secara visual (Sakinah, Rahmawati, Salman, \& Indorama, 2020) bagi yang melihat.

Desa Ngerangan saat ini dikenal sebagai desa cikal bakal angkringan dengan sebagian besar penduduknya berprofesi sebagai pedagang akringan yang tersebar di Indonesia (Klaten.go.id, 2020). Berawal dikenal sebagai desa cikal bakal angkringan, mulai pertengahan Tahun 2021 Desa Ngerangan melalui Badan Usaha Milik Desa atau BUMDes Ngerangan Jaya mengembangkan Desa Wisata Ngerangan dengan memanfaatkan potensi setiap wilayah dusun, diantaranya pembuatan blangkon di Dusun Wedutan, Kampung Jahe di Dusun Pilang, Kampung Pecel di Dusun Mojorejo, Kampung Tiwul di Dusun Keteng, dan angringan di Kampung Sawit (RadarSolo, 2021). Sebagai wisata yang baru berkembang, Desa Wisata Ngerangan memiliki beberapa masalah, berdasarkan analisa situasi dan wawancara dengan pengurus BUMDes Ngerangan Jaya yang telah dilakukan, salah satu permasalahan desa wisata 
ini kurangnya pemahaman warga tentang pemanfaatan teknologi informasi dalam pengembangan wisata yang berperan dalam memberikan informasi. Pemanfaatan teknologi untuk memberikan informasi atau bisa disebut digital marketing ini dapat memanfaatkan media sosial. Informasi yang diberikan melalui media sosial biasanya berupa dokumentasi atau foto, sehingga untuk menarik perhatian bagi sesama pengguna masing-masing media sosial tersebut dokumentasi tersebut harus memiliki kuatlitas yang baik dan unik yang bersifat menarik perhatian.

Ditinjau dari analisa situasi tersebut tujuan dari kegiatan ini membekali anggota aktif pengelola desa wisata setiap dusun dalam mempersiapakan dokumentasi atau foto yang berkualitas baik dan menarik untuk media sosial, selain itu kegitan ini merupakan salah satu solusi untuk mengatasi analisa situasi yang ditemukan. Kegiatan pengabdian masyarakat ini dilakukan di Desa Ngerangan, Kecamatan Bayat, Kabupaten Klaten oleh Tim Pengabdian Mayarakat Politeknik Manufaktur Ceper, dengan melakukan pelatihan teknik dasar fotografi dan editing yang digunakan sebagai dokumentasi pada media sosial.

\section{METODE}

Kegiatan pelatihan ini dilakukan hari Jum'at tanggal 22 Oktober 2021 secara tatap muka di Balai Desa Ngerangan, Kecamatan Bayat, Kabupaten Klaten, lokasi Google Maps ditunjukkan Gambar 1 (koordianat -7.802190130701364, 110.68570182331717) dengan menerapkan disiplin protokol kesehatan sesuai prosedur yang dianjurkan pemerintah. Kegiatan ini diikuti kurang-lebihr 30 ibu-ibu PKK Desa yang mewakili setiap dusun dan aktif dalam kegiatan. BUMDesa Pada pembekalan dan pelatihan ini dilakukan 2 sub-kegiatan, yaitu teknik fotografi dan teknik editing foto menggunakan aplikasi berbasis android Canva.

Pendekatan kegiatan ini untuk memenuhi tujuan dilaksanakan dalam beberapa sub-kegiatan, yaitu pemaparan yang menjelaskan latar belakang teknik dan editing fotografi, pelatihan dan pendampingan teknik teknik dan editing fotografi secara langsung, dan monitoring-evaluasi komunikasi efektif menggunakan aplikasi media sosial berbasis android WhatsApp dengan membentuk grup khusus monitoring dan pendampingan.

Tingkat keberhasilan kegiatan ini meliputi produk hasil teknik fotografi dan hasil editing fotografi layak digunakan sebagai media atau konten pada media sosial sebagai sarana promosi ataupun pengenal Desa Wisata maupun produk UMKM.

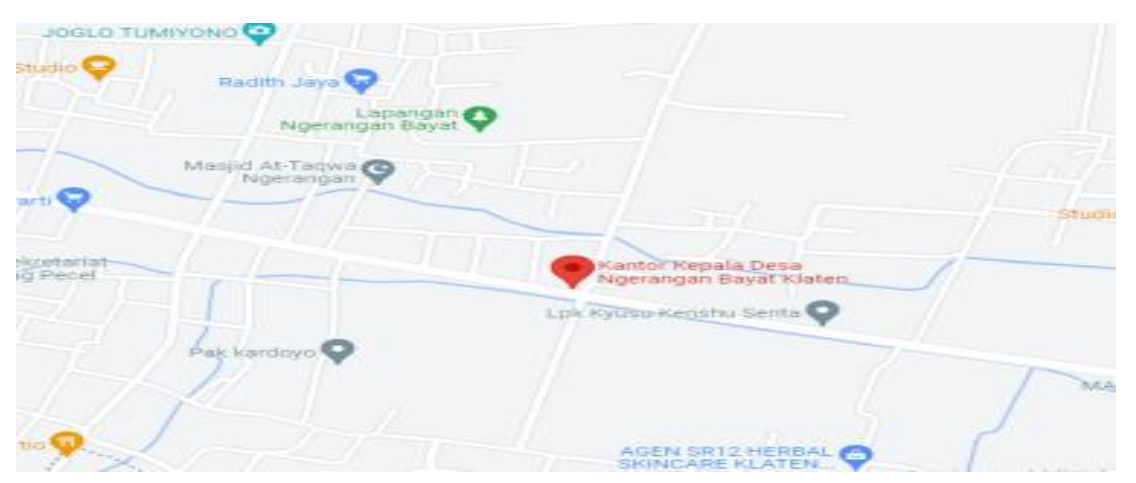

Gambar 1. Lokasi pelatihan berdasarkan Google Maps 


\section{HASIL DAN PEMBAHASAN}

\section{Pembekalan dan Pelatihan}

Kegiatan pembekalan dilakukan dengan metode presentasi seperti yang ditunjukkan Gambar 2, pemaparan ini menyampaikan teknik-teknik dasar fotografi yang meliputi kejelasan objek, pencahayaan obyek, background pendukung dan faktor lainnya untuk mendapat hasil dokumentasi foto yang berkualitas. Selain itu juga disampaikan teknik editing hasil dokumentasi foto menggunakan aplikasi berbasis android Canva agar lebih tertata dan menarik.

Teknik pencahayaan merupakan faktor paling mempengaruhi hasil dokumentasi foto, seperti yang ditunjukkan Gambar 3 pencahayaan lampu diperlukan saat dilakukan saat dilakukan fotografi dalam ruangan, selain itu Gambar 3 juga menunjukkan teknik penggunaan background polos berwarna putih cerah, hal ini dimaksudkan agar obyek utama terlihat fokus dapat terlihat jelas. Selain menggunakan background polos, background ini juga dapat dikombinasikan dengan obyek lain untuk menambah ketertarikan dalam dokumentasi foto, hal ini ditunjukkan Gambar 4 dengan menambahkan tangkai daun segar pada background.

Praktik teknik dan editining fotografi juga dilakukan secara langsung oleh peserta dan dibimbing secara langsung oleh tim pengabdian masyarakat. Gambar 5 menunjukkan praktik salah satu peserta untuk melakukan fotografi dengan teknik pencahayaan, Gambar 6 menunjukkan pendampingan langsung kepada salah satu peserta dalam mendoenload dan menggunakan aplikasi Canva. Sedangkan Gambar 7 menunjukkan salah satu peserta yang telah praktik teknik fotografi dan editing menggunakan aplikasi Canva.

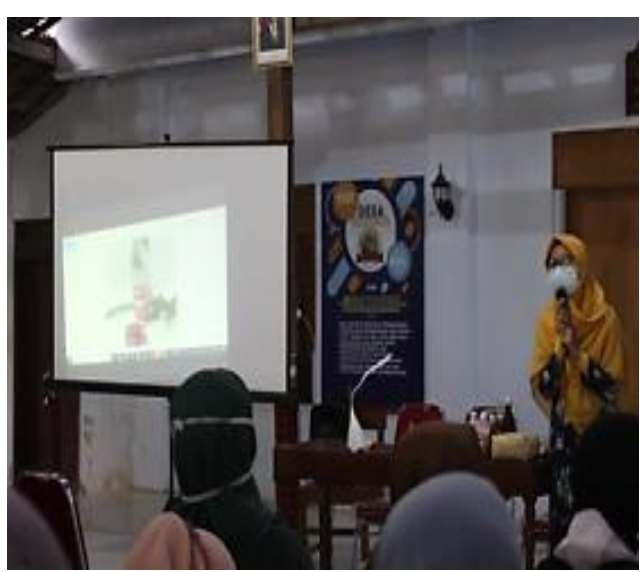

Gambar 2. Pembekalan materi tentang teknik fotografi dan editing

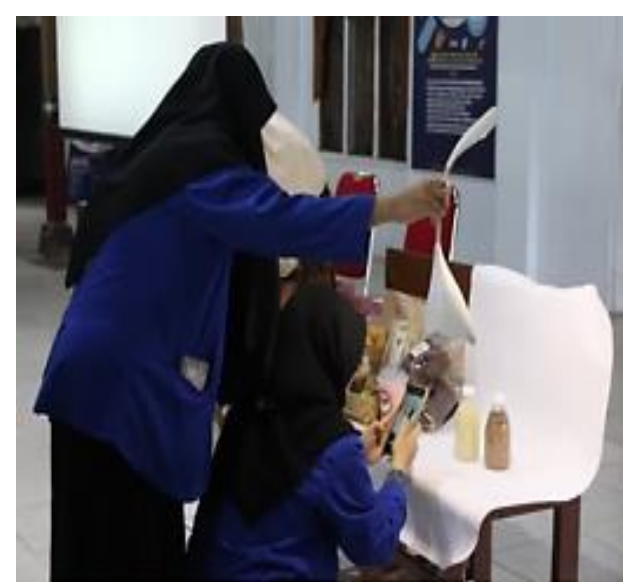

Gambar 3. Praktik teknik pencahayaan dan background 


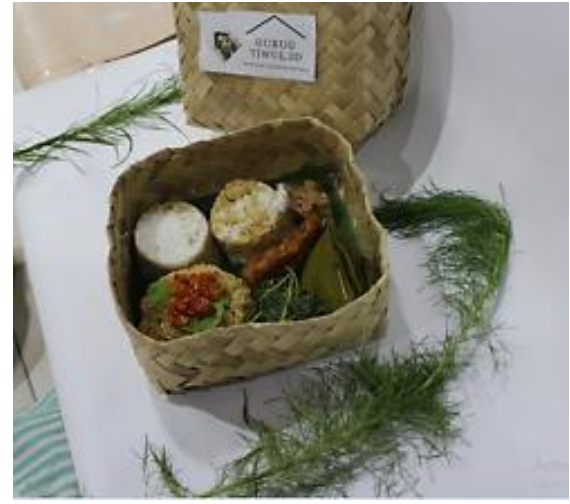

Gambar 4. Kombinasi background

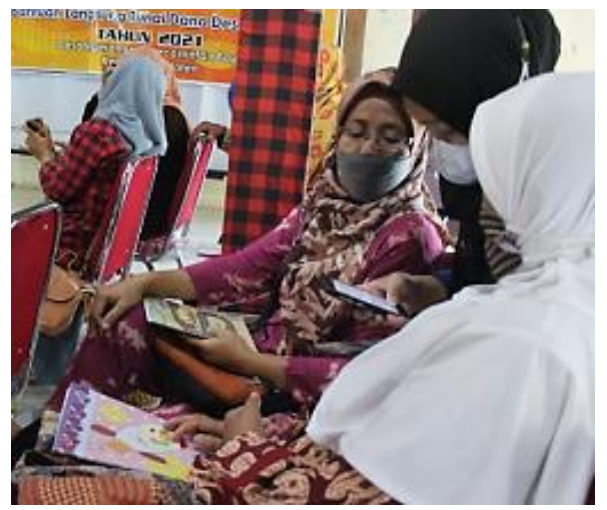

Gambar 6. Pendampingan mengoperasikan aplikasi Canva

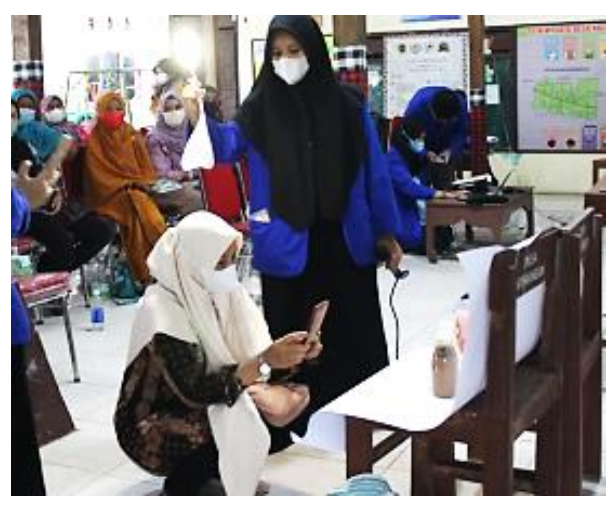

Gambar 5. Praktik peserta teknik fotografi

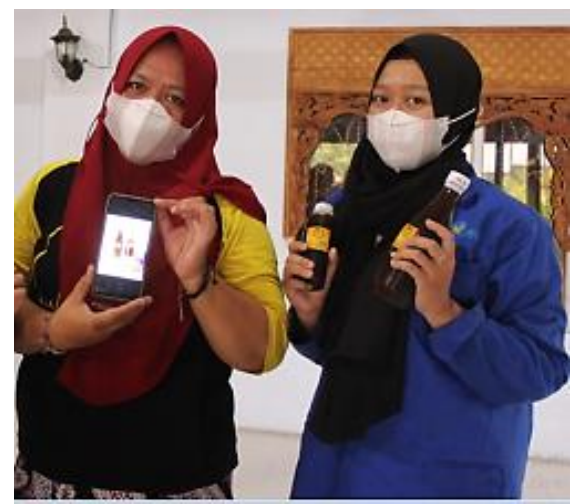

Gambar 7. Hasil praktik teknik fotografi dan editing

\section{Monitoring dan Pendampingan}

Setelah melakukan pembekalan materi dan pelatihan, tim pengabdian masyarakat melakukan monitoring dan pendampingan menggunakan media sosial WhatsApp. Melalui grup WhatsApp peserta aktif melakukan komunikasi dengan mengirimkan foto-foto sesuai dengan potensi daerah masing-masing dengan teknik yang telah dipelajari sebelumnya serta melakukan kreativitas menggunakan background yang telah disiapkan, selain itu peserta juga aktif mengirimkan foto yang telah diedit menggunakan aplikasi Canva.

Kegiatan pendampingan dilakukan saat peserta mengalami permasalahan maupun menanyakan sesuatu yang belum dipahami. Gambar 8 sampai Gambar 11 menunjukkan pilihan hasil fotografi, sedangkan Gambar 12 sampai 15 menunjukkan hasil editing foto mengunakan 
aplikasi Canva yang dikirim peserta pada WhatsApp grup setelah mendapatkan pendampingan tim pengambian masyarakat melalui komunikasi melalui WhatsApp grup pula.

Melalui kegiatan pelatiahan yang disertai dengan pendampingan dalam menerapkan teknik dasar fotografi dan editing, peserta dapat melakukan kreasi dalam mendokumentasi foto. Kegiatan ini merupakan bekal bagi peserta untuk menerapkannya dalam akun media sosial sebagai media promosi atau pengenalan Desa Wisata. Terdapat beberapa hambatan saat dilakukan kegiatan ini, diantaranya terdapat beberapa peserta yang memiliki smartphone dengan fitur kamera yang kurang, serta smartphone yang tidak support dengan aplikasi Canva.

Secara garis besar, program dan kegiatan masyarakat ini terlaksana dengan lancar dalam hal pelatihan secara langsung maupun monitoring melalui media sosial WhatsApp grup. Berdasarkan hasil fotografi dan hasil editing menggunakan aplikasi Canva dari peserta telah layak digunakan sebagai dokumentasi pengenalan atau promosi di akun media sosial.

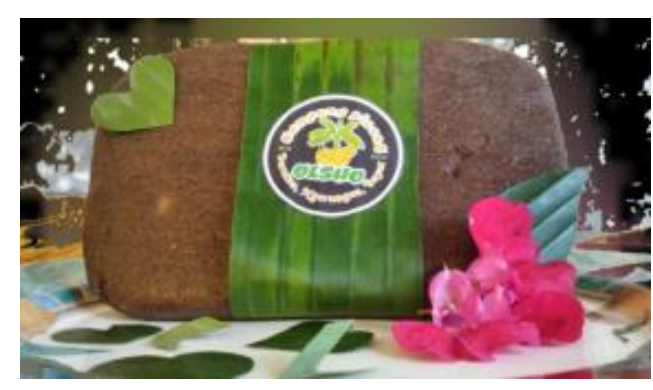

Gambar 8. Krasikan pisang dari Kampung Pisang

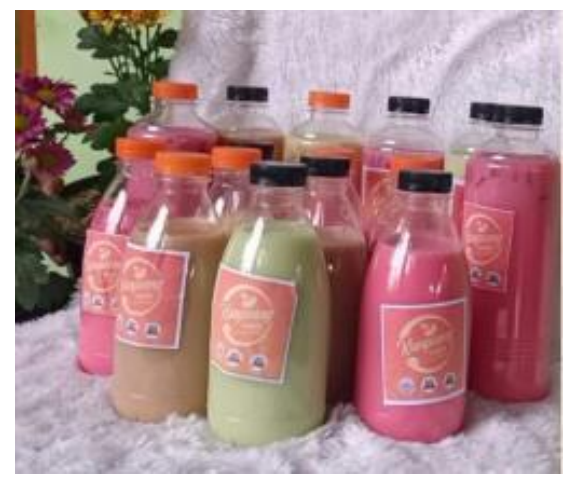

Gambar 10. Sari kedelei dari Kampung Kedelei RT 11 RW 05

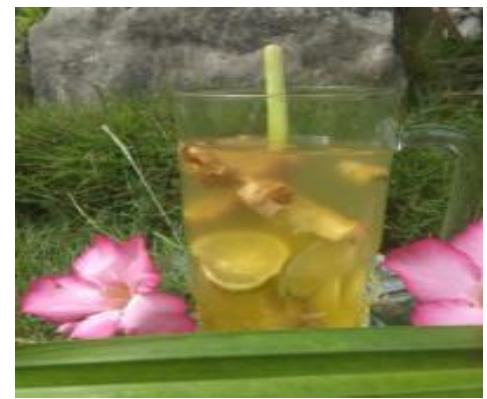

Gambar 9. Wedang Seruni dari Kampung Herbal RT 25 RW 11

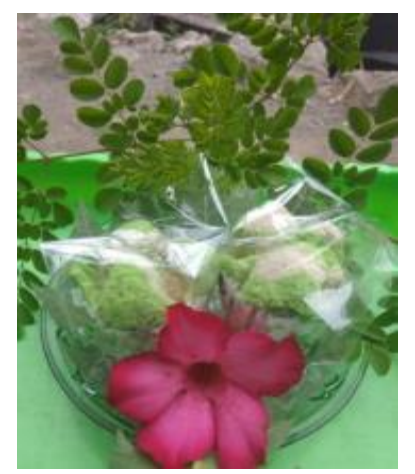

Gambar 11. Bolu kukus kelor dari Kampung Herbal RT 25 RW 11 


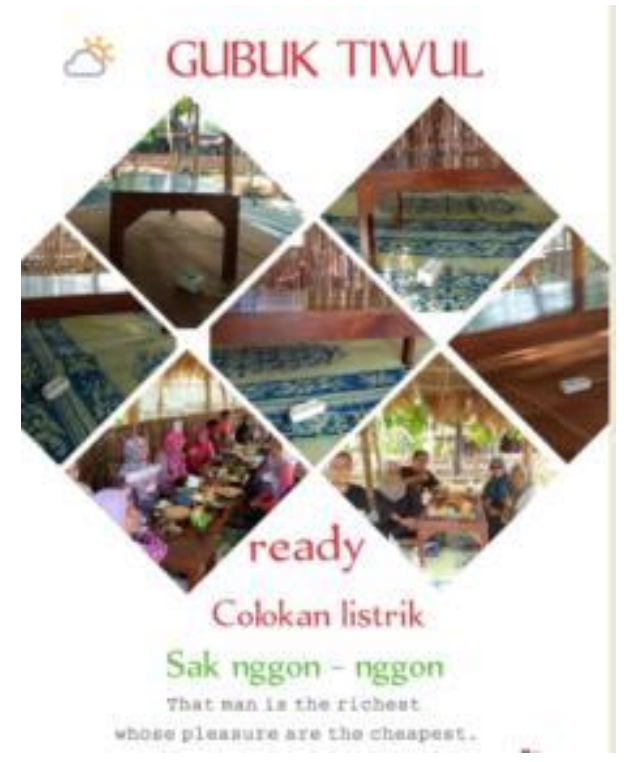

Gambar 12. Warung makan gubug tiwul RT 9 RW 2

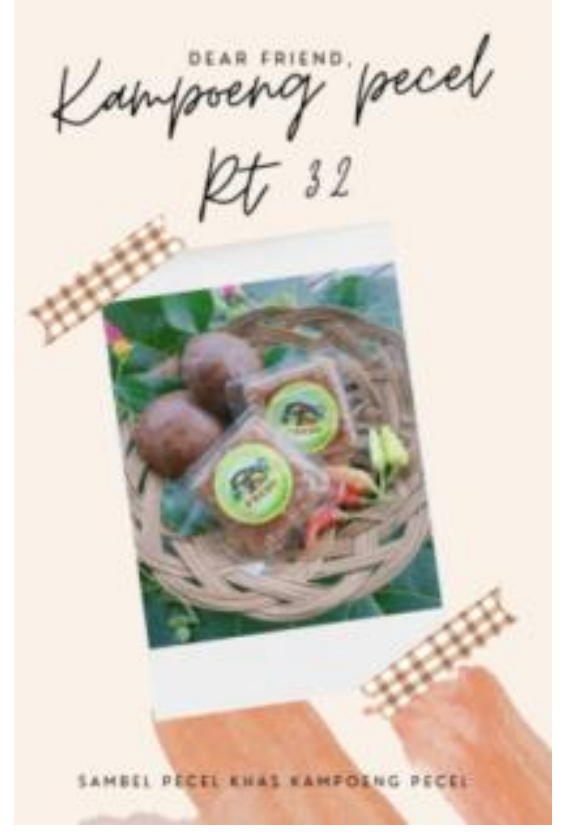

Gambar 14. Bumbu Pecel Kampung Pecel RT 32

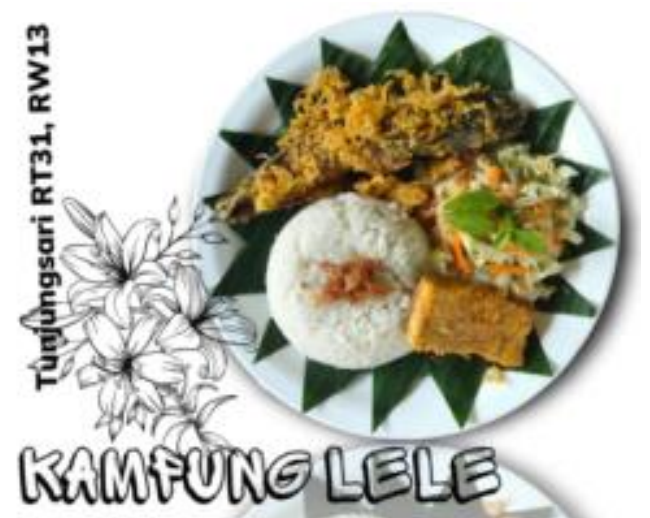

\section{Sasi lele fremes}

Gambar 13. Nasi lele kremes Kampung Lele RT 31 RW 13

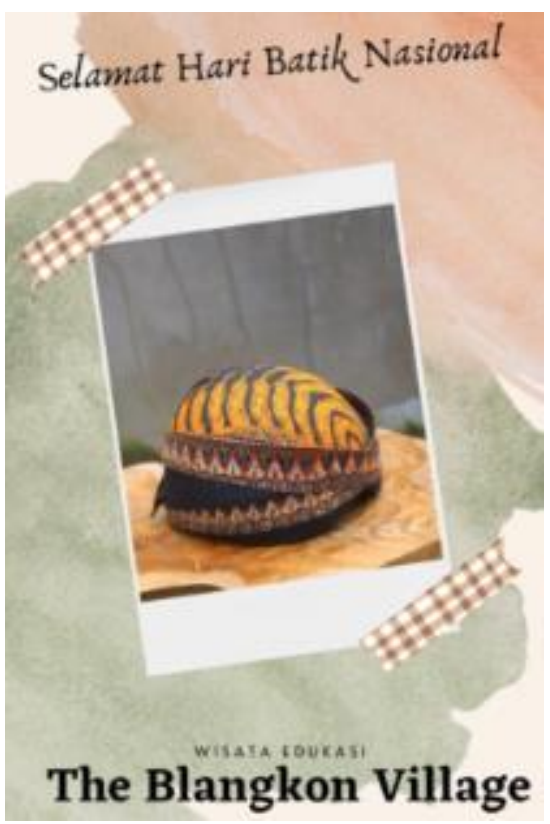

Gambar 15. Kerajinan blangkon Kampung Blangkom 


\section{KESIMPULAN}

Kegiatan pengabdian masyarakat telah dilakukan secara langsung di Balai Desa Ngerangan meliputi pembekalan materi dan pelatihan teknik fotografi dan editing menggunakan aplikasi Canva. Melalui kegiatan pemaparan materi, pelatihan teknik fotografiediting, dan monitoring-evaluasi menunjukkan adanya peningkatan kemampuan peserta dalam mendokumentasi obyek fotografi, serta menggunakan editing fotografi agar lebih kreatif dan menarik. Berdasarkan hasil fotografi dan editing yang dikirimakan peserta, kualitas foto maupun kreasi foto telah layak untuk dokumentasi pada akun media sosial sebagai media pengenalan atau promosi desa wisata.

\section{UCAPAN TERIMA KASIH}

Ucapan terima kasih penulis sampaikan kepada Politeknik Manufaktur Ceper melalui Lembaga Pengabdian Masyarakat yang telah mendanai program dan kegiatan pengabdian masyarakat ini. Selain itu penulis juga mengucapkan terima kasih kepada pemerintahan Desa Ngerangan yang telah memfasilitasi kegiatan ini.

\section{REFERENSI}

Arifah, F. N. (2015). Analisis Sosial Media Sebagai Strategi Marketing Dalam Bisnis Online. TRANSFORMASI Jurnal Informasi \& Pengembangan Iptek, 11(2), 143-149.

Atina, V. Z., \& Mahmudi, A. Y. (2019). Analisis Usia Dan Latar Belakang Pendidikan Terhadap Kesiapan Sdm Industri Ceper Di Era Revolusi Industri 4.0. Jurnal Education and Economics (JEE), 02(04), 495-500.

Atina, V. Z., Mahmudi, A. Y., \& Abdillah, H. (2021). Industry Preparation In Ceper Klaten On Society 5.0. International Journal of Economics, Business and Accounting Research (IJEBAR) Peer, 2021(2), 39-47.

Dewanti, G. K., \& Solihin, A. K. (2021). Pemanfaatan Instagram Business Sebagai Strategi. Jurnal PKM: Pengabdian Kepada Masyarakat, 04(01), 54-60.

ES., D. P., Rahmi, \& Aditya, S. (2017). Pemanfaatan Digital Marketing Bagi Usaha Mikro , Kecil , Dan Menengah ( Umkm ). Jurnal Pemberdayaan Masyarakat Madani (JPMM) Vol. 1, 1(1), 1-17.

Klaten.go.id. (2020). Ngerangan Klaten . Dikukuh Sebagai Cikal Bakal Desa Angkringan. https://klatenkab.go.id/ngerangan-klaten-dikukuh-sebagai-cikal-bakal-desa-angkringan/ 
Murwonugroho, W., \& Atwinita, S. (2020). Pelatihan penguatan teknik dasar fotografi dan teknik lampu studio pada sesi pemotretan model. Jurnal PKM: Pengabdian Kepada Masyarakat, 03(01), 114-122.

Nurhayati. (2018). Strategi Promosi Desa Wisata Kampung Badud Oleh Dinas Pariwisata Dan Kebudayaan Kabupaten Pangandaran. Dinamika: Jurnal Ilmiah Ilmu Administrasi Negara, 87-95.

RadarSolo. (2021). Ngerangan , Desa Cikal Bakal Angkringan Kini Moncer Jadi Kampung Wisata. https://radarsolo.jawapos.com/daerah/klaten/05/08/2021/ngerangan-desa-cikalbakal-angkringan-kini-moncer-jadi-kampung-wisata/

Sakinah, L., Rahmawati, N., Salman, H., \& Indorama, P. E. (2020). Pelatihan Desain Grafis Menggunakan Aplikasi Canva Tingkat Smk Di Smkn 1 Gunung Putri Bogor. BERNAS : Jurnal Pengabdian Kepada Masyarakat, 1(4), 476-480.

Tanjung, M. R. (2016). Fotografi Ponsel ( Smartphone ) Sebagai Sarana Media Dalam Perkembangan Masyarakat. Jurnal Proporsi, 1(2), 224-234.

Zakaria, F., \& Suprihardjo, D. (2014). Konsep Pengembangan Kawasan Desa Wisata di Desa Bandungan Kecamatan Pakong Kabupaten Pamekasan. Jurnal Teknik ITS, I 3(2). 